\title{
Neonatal Mortality Associated with the Referral of Low Birth Weight Newborns to the Institute of Child Nutrition and Health (INSE)
}

\author{
Diallo Ibrahima Sory 1,2, Diallo Sory², Conté N'fanly'2, Diawara Ibrahima², \\ Bah Elhadj Mamoudou ${ }^{3}$, Cissé Moussa ${ }^{2}$, Matthias Roth Kleiner ${ }^{4}$, Sy Telly ${ }^{3}$ \\ ${ }^{1}$ Pediatrics Chair, Gamal Abdel Nasser University, Conakry, Guinea \\ ${ }^{2}$ Institute of Nutrition and Child Health, Conakry, Guinea \\ ${ }^{3}$ Gyneco-Obstetrics Chair, Gamal Abdel Nasser University, Conakry, Guinea \\ ${ }^{4}$ Department of Women, Mother and Child, Lausanne, Switzerland \\ Email: diallopediatrie@yahoo.fr
}

How to cite this paper: Sory, D.I., Sory, D., N'fanly, C., Ibrahima, D., Mamoudou, B.E., Moussa, C., Kleiner, M.R. and Telly, S. (2019) Neonatal Mortality Associated with the Referral of Low Birth Weight Newborns to the Institute of Child Nutrition and Health (INSE). Open Journal of Pediatrics, 9, 287-295.

https://doi.org/10.4236/ojped.2019.94027

Received: September 26, 2019

Accepted: November 9, 2019

Published: November 12, 2019

Copyright $\odot 2019$ by author(s) and Scientific Research Publishing Inc. This work is licensed under the Creative Commons Attribution International License (CC BY 4.0).

http://creativecommons.org/licenses/by/4.0/

\section{c) (i) Open Access}

\begin{abstract}
The objective of this study was to identify risk factors and study the causes of neonatal mortality of LBW newborns referred to the Institute of Nutrition and Child Health. Material and Methods: This is a prospective descriptive and analytical study from March 1 to August 31, 2015, involving 250 newborns referred to the Neonatology Department of the Institute of Child Nutrition and Health (INSE). Results: During our study period, we recorded 1169 newborns, 250 of whom were referred, representing a referral frequency of $21.38 \%$. The overall mortality rate for transferring newborns was $46.8 \%$. Risk factors associated with neonatal mortality were gravidity $(p=0.0019)$, parity $(\mathrm{p}=0.0323)$, occupational activities requiring physical effort $(\mathrm{p}=$ $0.0257)$, birth weight $(\mathrm{p}=0.0008)$ and prematurity $(\mathrm{p}=0.0039)$. Conclusion: Neonatal mortality associated with referrals is a major health problem in developing countries. There is currently no doubt that it is possible to significantly reduce perinatal mortality and morbidity rates by organizing the identification of "mother-child" couples at risk, to refer them intently to centres better equipped with technical and human resources to care for them.
\end{abstract}

\section{Keywords}

Neonatal Mortality, Reference, Low Birth Weight, INSE

\section{Introduction}

Neonatal mortality is the total number of children born alive, but who died be- 
tween birth and the 28th day of life. It consists of "early neonatal mortality" for deaths in the first week, "late neonatal mortality" for those in the following three weeks [1]. In 2005, the World Health Organization (WHO) reported that of the 130 million children born each year worldwide, about 4 million die during the neonatal period and neonatal mortality increased from 37\% to 44\% from 1990 to 2012 [2]. Low birth weight (LBW) is a major public health problem and affects $17 \%$ of live births worldwide [3]. This frequency varies from $7 \%$ in developed countries to $19 \%$ in developing countries [4]. It is responsible for the deaths of 9.1 million children each year around the world [5]. The care required by these newborns is therefore at risk of becoming a burden on health and social systems and services around the world. Africa has the highest estimated neonatal mortality rate at 45 deaths per 1000 live births compared to 5 deaths in developed countries [6]. In Guinea in 2012, the Demographic Health Survey (DHS) reports that the neonatal mortality rate was $33 \%$ [7]. Neonatal mortality is still a real public health problem in the Republic of Guinea. Indeed, despite the remarkable progress made in the country, neonatal mortality is still high.

An examination of the evolution of neonatal mortality shows the extent of progress in this area. Indeed, over the past 24 years (1992 to 2016), neonatal mortality has risen from 66.6 deaths per 1000 live births to its current level $(20 \%)$ for the country. This improvement is noticeable in all administrative regions. The efforts made and progress made remain insufficient to meet the challenges ahead, and do not contribute sufficiently to the creation of an enabling environment. Newborn survival programmes face social norms and practices, the high cost of some services, and the remoteness or lack of health facilities nationwide. The inadequacy of the system of analysis and quality control at different levels of data collection and transcription, and the poor development of health research and particularly action research are factors limiting the identification and follow-up of newborns. Low educational attainment and lack of empowerment, prevent mothers from seeking timely health care and making the best choices for the health of their children, leading to dangerous delays and preventable deaths. The Institute of Child Nutrition and Health, being the only reference structure in Neonatology, receives nearly 1737 low birth weight babies per year referred by the health structures of the capital and those of the surrounding prefectures. Of these, 579 or $(0.33 \%)$ die on arrival or in hospital in the neonatal ward. This raises the following question: Why is the neonatal mortality so common among newborns of referring LBW? In an attempt to answer this question, we have set ourselves the objective of identifying risk factors and studying the causes of neonatal mortality in LBW newborns referred to the Institute of Child Nutrition and Health (Figure 1).

\section{Material and Methods}

This is a prospective descriptive and analytical study lasting 6 months from March 1 to August 31, 2015, involving 250 newborns referred to the Neonatology 


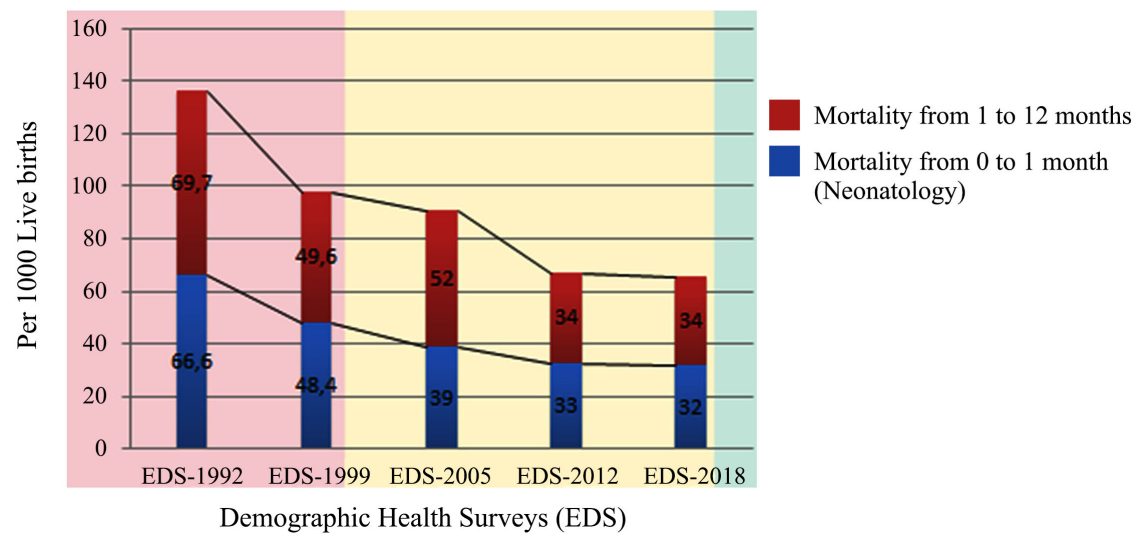

Figure 1. Neonatal mortality rate (2016) and its reduction (1992-2016).

department of the Institute of Child Nutrition and Health (INSE). INSE is a level 3 referral hospital in the Guinean health pyramid. It is located on the site of the Donka University Hospital Center, its vocation is to respond to emergency situations involving the pathologies of newborns and infants suffering from severe acute malnutrition and to offer nutritional advice to mothers on how to feed their children. This system, set up by a multidisciplinary team, offers 24 -hour care for children and newborns domiciled throughout the country. The study covered all low-birth-weight infants referred and who died in the Neonatology department of the INSE.

Not included were all deceased newborns with a birth weight greater than $2500 \mathrm{~g}$; low birth weights deceased not referred and body deposits.

Our data were collected from medical records, death records and individual survey sheets including questions on maternal characteristics (age, education, occupation, marital status, gestate and parity) and perinatal characteristics (time of admission, gestational age, birth weight and reference reasons). The data were entered and analyzed using Epi.info software version. 7.1. The association with mortality was measured with the Odds Ratio (OR) and its 95\% confidence interval was given. The materiality level is set at 0.05 .

Limits:

- Files sometimes incomplete.

- Means and reasons for reference not specified.

\section{Results}

During our study period, we recorded 1169 newborns, 250 of whom were referred, representing a referral frequency of $21.38 \%$. Of these referrals, we recorded 117 deaths, representing 46.8\% (Figure 2 and Table 1 ).

One hundred and thirty-two or $52.8 \%$ of referred newborns arrived at the centre by taxi and ambulance was used in $4.8 \%$ of cases. $40.40 \%$ of referring newborns came from maternity hospitals in university hospitals (CHU) and of these, $42.57 \%$ died ( $p=0.3733$ ), the difference observed was not statistically significant. 74.4\% newborns were referred by physicians (Table 2). 


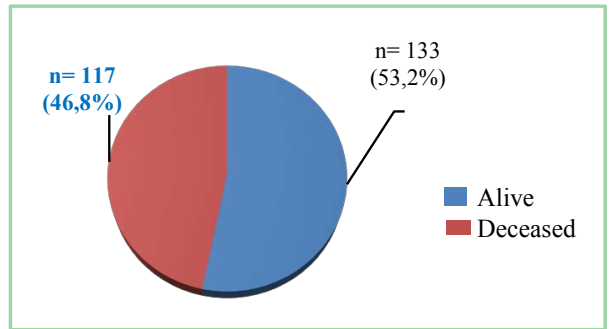

Figure 2. Death rates of referred newborns.

Table 1. Distribution of referred newborns by mode of transport and origin.

\begin{tabular}{cccc}
\hline Parameters & Deceased & Healing & p-value \\
\hline Transport & $3(25.00 \%)$ & $9(75 \%)$ & \\
Ambulance & $40(47.62 \%)$ & $43(52.38 \%)$ & 0.1352 \\
Feet & $64(48.48 \%)$ & $68(51.51 \%)$ & \\
Taxi & $10(45.45 \%)$ & $12(54.55 \%)$ & \\
Vehicle & & & \\
Provenance & $26(44.83 \%)$ & $32(55.17 \%)$ & \\
Clinic & $43(42.57 \%)$ & $58(57.4 \%)$ & \\
Hospital-University Center & $19(51.35 \%)$ & $18(48.65 \%)$ & \\
Medical-Communal center & $24(52.18 \%)$ & $22(47.82 \%)$ & \\
Health Center & $5(62.50 \%)$ & $3(37.50 \%)$ & \\
Residence & & \\
\hline
\end{tabular}

Table 2. Distribution of newborns by maternal parameters.

\begin{tabular}{|c|c|c|c|}
\hline Parameters & Deceased & Healing & $\mathrm{p}$-value \\
\hline \multicolumn{4}{|l|}{ Parity } \\
\hline Multipare & $56(54.37 \%)$ & $46(45.63 \%)$ & \multirow{3}{*}{$\begin{array}{c}\mathrm{p}=0.0323 \\
\mathrm{OR}=1.73(1.04-2.88)\end{array}$} \\
\hline Small pare & $25(41.67 \%)$ & $35(58.33 \%)$ & \\
\hline Primipares & $386(41.38 \%)$ & $51(58.62 \%)$ & \\
\hline \multicolumn{4}{|l|}{ Year } \\
\hline$<18$ & $16(42.11 \%)$ & $22(57.89 \%)$ & \multirow{3}{*}{0.3791} \\
\hline $18-35$ & $6(60.00 \%)$ & $4(40.0 \%)$ & \\
\hline$>35$ & $9(47.03 \%)$ & $107(52.07 \%)$ & \\
\hline \multicolumn{4}{|l|}{ Schooling } \\
\hline Not in school & 76 (50.67\%) & $74(49.33 \%)$ & \multirow{3}{*}{0.0894} \\
\hline Secondary school & $4(28.57 \%)$ & $10(71.43 \%)$ & \\
\hline Superior & $37(43.02 \%)$ & $49(56.98 \%)$ & \\
\hline \multicolumn{4}{|l|}{ Status } \\
\hline Married & $103(48.58 \%)$ & $109(51.14 \%)$ & \multirow{2}{*}{0.0926} \\
\hline Single & $14(36.84 \%)$ & $24(63.15 \%)$ & \\
\hline \multicolumn{4}{|l|}{ Profession } \\
\hline Housewife & $44(45.83 \%)$ & $52(54.16 \%)$ & \multirow{5}{*}{$\begin{array}{c}0.0257^{\star}(\mathrm{OR}=2.24) \\
(1.10-4.58)\end{array}$} \\
\hline Merchant & $41(52.56 \%)$ & $37(47.44 \%)$ & \\
\hline Student & $19(40.43 \%)$ & 0 & \\
\hline Cultivator & $1(100.00 \%)$ & $28(59.58 \%)$ & \\
\hline Others & $12(42.86 \%)$ & $16(57.14 \%)$ & \\
\hline
\end{tabular}

\subsection{Maternal Characteristic}

The average maternal age was $23.62 \pm 5.41$ years with extremes ranging from 17 to 45 years. Neonatal mortality was more frequent (60\%) among newborns born 
to mothers aged 18 to 35 years $(\mathrm{p}=0.3791) .60 \%$ of referred newborns came from mothers who were not in school and the mortality rate was $50.66 \%$ ( $\mathrm{p}=$ $0.0894)$, the difference observed was not statistically significant. We recorded $45.83 \%$ deaths among newborns born to housewives $(\mathrm{p}=0.0257)(\mathrm{OR}=2.24)$ (1.10 - 4.58), the difference observed was statistically significant. 212 referred newborns or $84.8 \%$ were from married mothers, of whom we recorded 103 deceased newborns or $48.58 \%(\mathrm{p}=0.0926)$, the difference observed was not statistically significant.

\subsection{Characteristics of Newborns}

Table 3 shows that the time of admission 24 hours was $45.29 \%$ of deceased newborns compared to $59.26 \%$ for those whose time of admission was $>24$ hours $(\mathrm{p}=0.2240)$, the difference observed was not statistically significant. The sex ratio was 1.48. The mean gestational age was 34.54 Amenorrhea Week (AW) \pm 2.34 with extremes of 27 to 39 Gestational Age (GA).

The mortality rate among children born between 32 nd and 37 th GA was $70 \%$ $(p=0.9460)$, the difference observed was not statistically significant. $9.20 \%$ of the referred children weighed less than $1000 \mathrm{~g}$ and of these $95.65 \%$ died ( $\mathrm{p}=$ $0.0008)$, the difference observed is statistically very significant. $40.38 \%$ were referred for prematurity with a mortality rate of $40.38 \%$ ( $p=0.0039$ ), the difference observed was statistically significant. $59.55 \%$ of the deceased newborns were from multi-gesture mothers compared to $43.33 \%$ for those from small-gesture mothers and $37.62 \%$ for those from multi-gesture mothers ( $\mathrm{p}=$ $0.0323)(\mathrm{OR}=1.73(1.04-2.88))$.

Table 3. Distribution of newborns by characteristic.

\begin{tabular}{|c|c|c|c|}
\hline Parameters & Deceased & Healing & $\mathrm{p}$-value \\
\hline \multicolumn{4}{|l|}{ Admission deadline } \\
\hline$<24$ & $101(45.29 \%)$ & $122(54.71 \%)$ & \multirow{2}{*}{0.1554} \\
\hline$>24$ & $16(59.26 \%)$ & $11(40.74 \%)$ & \\
\hline \multicolumn{4}{|l|}{ Gender } \\
\hline Male & $70(49.65 \%)$ & $71(50.36 \%)$ & \multirow{2}{*}{0.2240} \\
\hline Female & $47(43.12 \%)$ & $62(56.88 \%)$ & \\
\hline \multicolumn{4}{|l|}{ Gestational Age (GA) } \\
\hline$<28$ & $33(47.14 \%)$ & $37(52.86 \%)$ & \multirow{4}{*}{0.9460} \\
\hline $28-32$ & $68(43.31 \%)$ & $89(56.69 \%)$ & \\
\hline $32-37$ & $14(70.00 \%)$ & $1(30.00 \%)$ & \\
\hline$>37$ & $2(66.67 \%)$ & $1(33.33 \%)$ & \\
\hline \multicolumn{4}{|l|}{ Weight } \\
\hline$<1000$ & $22(95.65 \%)$ & $1(4.35 \%)$ & \multirow{3}{*}{$0.0008^{*}$} \\
\hline $1000-1500$ & $49(39.84 \%)$ & $74(60.16 \%)$ & \\
\hline $1500-2499$ & $46(44.23 \%)$ & $58(55.77 \%)$ & \\
\hline \multicolumn{4}{|l|}{ Reason } \\
\hline Prematurity & $42(40.38 \%)$ & $62(59.62 \%)$ & \multirow{4}{*}{$0.0039^{*}$} \\
\hline Infection & $33(50.00 \%)$ & $33(50.00 \%)$ & \\
\hline Respiratory Distress & $24(53.33 \%)$ & $21(46.66 \%)$ & \\
\hline Low Birth Weight & $18(51.42 \%)$ & $17(48.56 \%)$ & \\
\hline
\end{tabular}




\section{Discussion}

Neonatal mortality associated with referrals is a major health problem in developing countries. The mortality rate for newborns referred to the INSE is (46.8\%). This rate is higher than those found by Bobossi, G. (41.3\%) in Bangui, Senga, P. (45.7\%) in Brazzaville, Tietche, F. (36.1\%) in Yaoundé, and Keita, M. (35.9\%) in Bamako [8] [9] [10] [11]. The high death rate of low birth weight newborns in our series is believed to be due to family poverty, delays in making decisions about newborn care, but also the use of transportation to reach health facilities. Taxis and walking are most often the means of evacuation and ambulances were used in only $4.8 \%$ of cases. These results are contrary to those found by Kataméa, T. et al. who observed a $26.7 \%$ rate of public transport use and in the majority of cases the transport was done on foot, in no case was the ambulance used. In Guinea, the majority of outlying maternity hospitals are not specialized means of transport for the transfer of newborns; hence, newborns are transferred into the hands of parents either by public transport or on foot, exposing them to hypothermia and hypoglycemia because they do not benefit from thermal blankets or any treatment along the way to health services. Physicians were the most represented referring agents $(74.4 \%)$ due to the fact that most newborns come from university hospitals where only physicians are authorized (most often) to refer [12]. This result is similar to that of Traoré, D. et al. who found that $70.3 \%$ of newborns were referred by physicians. As for the marital status of mothers, we found that it was not associated with the occurrence of death among referred newborns $(\mathrm{p}=0.0926)$. With regard to the occupation of mothers, we observed that it is newborns born to working mothers who die much more than those born to housewives $(\mathrm{p}=0.0257)$ [13]. The same observation was made by Kataméa, T. et al. who found that newborns from working mothers died more than those from housewives $(\mathrm{p}=0.0246)$ and had a 7 -fold risk of death $(\mathrm{OR}=7.43(1.38-39.97))[12]$. This would be explained by the fact that the level of education is often correlated with the profession; that is, a female worker at a certain level of education. Several studies conducted around the world have shown that a working woman (i.e., a woman who has an occupation) is subject to a number of occupational risks: stress, intense physical work, organizational constraints, chemicals, biological agents, radiation; the involvement of these occupational risks, especially stress (physical or psychological) in the occurrence of low weight in general and in preterm birth in particular, has been widely discussed in several studies [14] [15]. In our study, we also found that age and education were not associated with the occurrence of neonatal deaths (see Table 2). On the other hand, parity was associated with neonatal death ( $\mathrm{p}=$ $0.0323)$ with $\mathrm{OR}=1.73(1.04-2.88)$ [12]. At the Katamea, T. et al. study, the mean parity was $3.3 \pm 2.0$ ranging from 1 to 9 in the deceased newborn group while it was $3.2 \pm 2.5$ ranging from 1 to 12 in the healed group, no significant differences were found when comparing the two means $(t=0.05 ; \mathrm{p}=0.9573)$ [12]. Concerning the admission time, we found that $89.2 \%$ of newborns were 
admitted within the first 24 hours of life with a mortality rate of $45.29 \%$ and Those who were admitted after 24 hours represented $10.8 \%$ with a mortality rate of 59.29\% ( $p=0.2240$ ), the difference observed was not statistically significant. Faye, P.M. in Senegal observed that the average age at the time of transfer was 72 hours ( 1 hour to 28 days of life), and early transfers before 48 hours (68 cases) represented 52.3\%. The mean gestational age in our series was $34.54 \mathrm{WA} \pm 2.34$ with a higher mortality rate among newborns of gestational age $\geq 37(0.9460)$ [16]. Our result is consistent with that of Onwuanaku who observed that the neonatal death tended to occur more at gestational l'âge less than 37 weeks, although gestational age is not significantly related to neonatal mortality [17]. However, S. Diallo et al. observed in their study that newborns of gestational age 37 WA were 7.6 times more likely to die than those of gestational age $\geq 37$ SA (p $=0.001$ ) [18]. In the study by Katamea, T., et al., the proportion of deaths was higher among newborns whose gestational age was 37 WA with a risk of 3 times $(\mathrm{p}=0.05)$. In our environment, as in most developing countries characterized by impoverished and under-equipment of health facilities, the rearing of premature babies poses serious problems and premature birth is associated with a high rate of neonatal death. The high rate of preterm lethality observed in our study is explained by the fact that, from birth to admission to our service, the preterm infant does not benefit from any continuing care as he deserves, knowing that he is physiologically immature in all organs (pulmonary immaturity, low carbohydrate reserves, immaturity of thermo regulation, immunological immaturity, neurological immaturity) [12]. The distribution of deaths by birth weight shows that $95.65 \%$ of deaths are attributable to at least $1000 \mathrm{~g}, 39.84 \%$ for those between 1000 and $1500 \mathrm{~g}$ and 44.23\% for newborns over $1500 \mathrm{~g}$. In Martinique, in the study concerning the children of gestational age $\leq 32$ WA, Masson, P. et al. found a mortality rate of $16.3 \%$ to $53 \%$ for those under $1000 \mathrm{~g}$ and $14 \%$ for those with a birth weight $>1000 \mathrm{~g}$ [19]. In Reunion Island, in a study on the mortality and short-term fate of low birth weight newborns $\leq 1500 \mathrm{~g}$ Tilmont et al. found an overall mortality of $16.5 \%$ to $42.6 \%$ in newborns of birth weight $\leq 1000 \mathrm{~g}$ and 9.9\% for those weighing between 1000 and $1500 \mathrm{~g}$. Among the pathologies responsible for death in referring newborns, four share the majority: respiratory distress (53.33\%), IUGR (51.42\%), prematurity (40.38\%), maternal-fetal infections (50\%) [20]. Tieche et al. found bacterial infections (52\%), apnea (19.75\%) and respiratory distress $(11.1 \%)$ as the main causes of death [10].

\section{Conclusion}

This work has shown us that the mortality rate of low birth weight newborns referred to the Institute of Nutrition and Child Health remains high. This neonatal mortality is the result of a combination of factors largely related to transfer conditions, lack of neonatal resuscitation equipment, birth weight and prematurity. The distance from the peripheral centres of the reference maternity units and the transfer under poor conditions lead to a risk of aggravation of the newborn's 
condition. There is currently no doubt that it is possible to significantly reduce perinatal mortality and morbidity rates by organizing the identification of "mother-child" couples at risk, to refer them intently to centres better equipped with technical and human resources to care for them.

\section{Conflicts of Interest}

The authors declare no conflicts of interest regarding the publication of this paper.

\section{References}

[1] Fossier, R. (1997) La petite enfance dans l'Europe médiévale et modern. Presses Universitaires du Mirail, Toulouse Cedex, 194.

[2] WHO (2005) World Health Report 2005: Making Every Mother and Child Count. WHO, 99-111.

[3] Dao, A. (2006) Immediate Becoming of Newborns Transferred from the Maternity Ward to the Neonatology Unit of the CHU-YO and the Neonatology Unit of the Saint-Camille Medical Center. UFR/SDS, Ouagadougou, 71, 55 p.

[4] Dumont, M. and Mazuèz, M. (1985) Study of the Etiological Factors of Fetal Hypotrophy. About 600 Observations. Journal de Gynécologie Obstétrique et Biologie de la Reproduction, 14, 439-448.

[5] Bobossi, S.G., Mbongo, A.N., Kalambay, K., Diemer, H. and Siopathis, R.M. (1999) Mortality Factors for Low Birth Weight Newborns in Semi-Rural Central African Countries. Médecined'Afrque Noire, 46, 446-450.

[6] WHO Africa (2004) Roadmap for Achieving the Millennium Development Goals Related to Maternal and Newborn Health in Africa.

[7] Ministry of Planning and International Cooperation (2016) Demographic and Health Survey (Guinea).

[8] Bobossi, G., Mbongo, Z.A., Diemer, H., Nadji, A.F. and Siopathisr, M. (2000) Low Birth Weight Newborns at the Neonatology Unit of the Bangui Pediatric Complex (CAR): Becoming Immediate and Prognostic. Pub Méd Afrique, 192-195.

[9] Senga, P., Mayanda, H.F., Djouob, S. and Malonga, H. (1989) Low Birth Weight in Brazzaville: Determinant Factors, Immediate Prognosis. Pub Méd Afrique, 102, 20-23.

[10] Tietche, F., Koki, N.P., Kago, I., Angaye, Y.Y., Ndoumbe, P., et al. (1994) Mortality Factors for Low Birth Weight Infants at Yaoundé Central Hospital. Annales de pédiatrie, 41, 253-259.

[11] Keita, M., Samake, M. and Dao, A. (1992) Low Birth Weight Babies in Bamako: Becoming Immediate. Pub Méd Afrique, 11, 11-16.

[12] Katamea, T., Mukuku, O., Kamona, L., Mukelenge, K., Mbula, O., Baledi, L., et al. (2014) Mortality Risk Factors in Newborns Transferred to the Neonatal Unit at Jason Sendwe Hospital in Lubumbashi, Democratic Republic of Congo. Pan African Medical Journal, 19, 169. https://doi.org/10.11604/pamj.2014.19.169.4018

[13] Dicko Traoré, F., Sylla, M., Diakité, A.A., Soilihi, A., N’Diaye, M.D., Togo, B., Diakité, F.L., Konaté, D., Traoré, B., Sidibé, T. and Keita, M.M. (2010) Problems of the Neonatal Transfer to the Paediatric Ward of the Gabriel Touré University Hospital in Bamako. Le Mali medical, 25, 25-28.

[14] Dole, N., Savitz, D.A., Hertz-Piccioto, I., Siega-Riz, A.M., McMahon, M.J. and Bu- 
enkens, P. (2002) Maternal Stress and Preterm Birth. American Journal of Epidemiology, 157, 14-24. https://doi.org/10.1093/aje/kwf176

[15] Epiney, M., Boulvain, M. and Irion, O. (2011) Psychosexual Risk Factors and Psychotherapy and Preterm Delivery. Revue Médicale Switzerland, 7, 2066-2069.

[16] Faye, P.M., Dieng, Y.J., Diagne-Guèye, N.R., Guèye, M., Bâ, A., Seck, M.A., et al. (2016) Neonatal Transfer Issues in the Dakar Region (Senegal). Revue de médecine périnatale, 8, 94-102. https://doi.org/10.1007/s12611-016-0353-4

[17] Onwuanaku, C.A., Okolo, S.N., Ige, K.O., Okpe, S.E. and Toma, B.O. (2011) The Effects of Birth Weight and Gender on Neonatal Mortality in North Central Nigeria. BMC Research Notes, 4, 562. https://doi.org/10.1186/1756-0500-4-562

[18] Diallo, S., Fofana, B., Bangoura, M.M., Kaba, M.L., Michel, W. and Kassé, D. (2002) Mortality Factors for Newborns with Low Birth Weight at the Hospital in Kamsar, Guinea. Médecined'Afrque Noire, 49, 250-253.

[19] Masson, P. and Cecille, W. (1998) Mortality, Morbidity and Short-Term Neurological Development of Gestational Age Children $\leq$ at $32 \mathrm{SA}$ at the $\mathrm{CHU}$ de Fort-de-France. Archives de Pédiatrie, 5, 865-868.

https://doi.org/10.1016/S0929-693X(98)80127-9

[20] Tilmon, P., Rose Wolter, M., Alessendri, J. and Bratzlawsky, C. (1995) Mortality and Becoming Short-Term Newborns of Weight $\geq$ to $1500 \mathrm{~g}$ at the Reunion. Archives de Pédiatrie, 2, 598-600. https://doi.org/10.1016/0929-693X(96)81209-7 